\title{
Letting Go of Your Losses: Experimental Evidence for Debiasing the Disposition Effect in Private Investment Decisions
}

\author{
Christoph Döbrich ${ }^{1,2}$, Jutta Wollersheim ${ }^{1,2}$, Matthias Spörrle ${ }^{3} \&$ Isabell M. Welpe \\ ${ }^{1}$ Technische Universität München, Chair for Strategy and Organization, Arcisstraße 21, 80333 München, Germany \\ ${ }^{2}$ Both authors contributed equally to this work and should be considered co-first authors. \\ ${ }^{3}$ University of Applied Management, Am Bahnhof 2, 85435 Erding, Germany \\ Correspondence: Christoph Döbrich, Technische Universität München, Chair for Strategy and Organization, \\ Arcisstraße 21, 80333 München, Germany. Tel: 49-89-289-24800. E-mail: c.doebrich@gmail.com
}

Received: August 16, 2014

Accepted: September 5, 2014

Online Published: October 16, 2014

doi:10.5430/jms.v5n4p1

URL: http://dx.doi.org/10.5430/jms.v5n4p1

An earlier version of this article has been part of Christoph Döbrich's dissertation: http://nbn-resolving.de/urn/resolver.pl?urn:nbn:de:bvb:91-diss-20121219-1120888-0-4.

\begin{abstract}
This study examines the impact of two different debiasing interventions on the emergence of the disposition effect in the investment decisions of private investors. By means of a fully crossed 2 x 2 between-participants online experiment $(N=223)$ and an established stock market simulation task, we examine the potential debiasing effects of rational warnings and emotional warnings on the emergence of the disposition effect. The disposition effect was successfully eliminated by both debiasing strategies. The simultaneous presence of both interventions did not increase the solitary effect of each of the two interventions.
\end{abstract}

Keywords: Investment decision, private investor, private stock trading, investment strategy, disposition effect, bias, decision-making, debiasing

\section{Introduction}

Over the past decades, an increasing number of non-professional individuals have become attracted by the convenience of online trading (Konanaa/Balasubramanian 2005) and now regularly make their own investment decisions, e.g., regarding their contributions to pension arrangements (Bhandari et al. 2008). Trust in institutional investors has generally decreased, because many of these institutional investors have been unable to protect their clients from the effects of the recent financial crisis (Glode 2011). As a result of these developments an increasing number of individuals take their financial matters into their own hands and engage more frequently in investment decisions with all the inherent risks and uncertainties.

When making investment decisions, people often act irrationally (Baker/Nofsinger 2002; Stanovich/West 2000; Von Neumann/Morgenstern 1944), e.g., by buying a disproportionately high number of stocks of companies headquartered in their own country although the benefits of international diversification are well-known (cf. Baker/Nofsinger 2002). Such irrational decisions, in turn, lead to poor financial returns (Lee et al. 2008; Odean 1998; Roger 2009). Scholars have analyzed the effect of such systematic deviations from rational judgment and decision making on financial returns (e.g., Benartzi/Thaler 2001; Deaves 2004). However, it is not sufficient to identify biases and to investigate their impact on financial returns; instead we must determine what can be done to counteract such biases. This is of major importance for financial institutions and private investors alike, because counteracting such biases should, for instance, generally lead to higher performance in portfolios and stabilize financial markets.

One promising suggestion to counteract biases in investment decision making contexts is to use debiasing strategies, i.e., "intervention[s] that correct [..] the error which causes the biased judgment in the first place" (Soman/Liu 2011, p. 309). Scholars have previously noted the effectiveness of supporting investors' investment decisions through debiasing (e.g., Milkman et al. 2009), and initial studies have already shown that debiasing has the potential to lower biases in investment decisions (e.g., Fennema/Perkins 2008; Ghosh 1997; Simonson/Nye 1992). Scholars have also 
begun to investigate debiasing regarding the disposition effect (i.e., "the tendency to sell winners too early and ride losers too long", Shefrin/Statman 1985, p. 777). On an organizational level, previous research in this field has discovered the following two ways to reduce the disposition effect: (1) clouding fund managers' memories by introducing a regular rotation of fund managers and traders in investment companies (Camerer 2003, p. 15) and (2) relying on objective data and quantitative decision models rather than on subjective judgments in mutual fund investment decisions (Ringov 2012). Although these findings enhance our understanding of debiasing the disposition effect at institutional and organizational levels, the findings do not help in understanding the decision making of individual investors. First, private investors can usually neither change trading accounts with someone else (although they might sometimes share trading accounts, for example, with family members or in investor clubs, of course) nor cloud their memories to supersede their existing knowledge on the values at which they initiated certain stock positions in their portfolio. Second, most of these investors do not and cannot implement different formal models in an organizational decision-making process to avoid subjective judgments when making their investment decisions.

On an individual level, Lee et al. (2008) found that participants who were trained in probability-expectancy calculation did not demonstrate the disposition effect. Das (2012) found the disposition effect to be considerably smaller when delaying the sales of profitable stocks beyond their actual selling dates. In his simulation study, Das (2012) additionally observed that automatically selling stocks that had increased or decreased $25 \%$ from their initial prices fully eliminates the losses caused by the disposition effect (cf. Richards et al. 2011). Similarly, Weber/Camerer (1998) observed that automatically selling stocks effectively lowered the disposition effect. Although these findings provide some evidence for lowering the negative consequences of the disposition effect on an individual level, they have a number of disadvantages in practice. First, investors might not be willing to complete training in probability-expectancy calculation as suggested by Lee et al. (2008). Additionally, the majority of investors might not be willing to forgo the possibility of making their own selling decisions anytime and might thus neglect automatic trading mechanisms, which, once voluntarily ordered, are processed without unique selling decisions made by the investors. Second, automatic selling decisions do not address the cognitive emergence of the disposition effect per se but rather address the negative consequences of the disposition effect by cutting back the freedom of decision. For investors who are willing to complete training in probability-expectancy calculation as suggested by Lee et al. (2008), there is an initially promising intervention at hand that appears to address the cognitive emergence of the disposition effect. However, research on this topic is very limited and we lack insights into debiasing strategies that (1) address the cognitive emergence of the disposition effect, (2) are easy to implement by financial institutions for all their private investors, and (3) have the potential to be broadly accepted by individual investors.

In sum, despite the fact that the disposition effect is considered as one of the most pervasive biases in investment decisions, research has not identified an easy-to-implement debiasing strategy that successfully addresses the cognitive emergence of the disposition effect and that might be broadly accepted at the individual investor level. This research gap is important because it is well documented that private (as well as institutional) investors regularly fall prey to this bias (Barber et al. 2007; Coval/Shumway 2005; Genesove/Mayer 2001; Lehenkari/Perttunen 2010; Odean 1998; Shapira/Venezia 2001) and its emergence "has been documented across many financial markets" (Das 2012, p. 1). Furthermore, this research gap is of major importance because investment decision errors are costly. As one previous study notes, "investors reach a lower level of welfare and the loss of welfare increases with the intensity of the disposition effect" (Roger 2009, p. 139).

This study addresses the research gap by extending the established Weber/Camerer (1998) experiment by analyzing two different easy-to-implement debiasing strategies that aim to alleviate the disposition effect in the individual investment decisions of private investors. Our results shed light on the understudied area of lowering the emergence of the disposition effect (rather than limiting its consequences), thereby contributing to the enhanced investment decisions of private investors and providing a basis for a potential reduction of the disposition effect in managerial investment decisions as well.

This paper is organized as follows: In the next section, we discuss the relevant literature used in the development of our hypotheses. We then present our experimental design and describe our findings. The paper concludes with a discussion of the results obtained and a summary of the study's theoretical and practical implications.

\section{Theoretical Foundations and Hypotheses}

\subsection{The Emergence of the Disposition Effect}

An increasing number of private investors have begun to trade online (cf. Barber/Odean 2001; Konanaa/Balasubramanian 2005). Although trading online certainly has some advantages, such as, for example, lower trading costs, cognitive biases appear to be even more pronounced in online trading (Barber/Odean 2002). The 
disposition effect has been shown to emerge in many different areas of investment decisions, such as housing markets (e.g., Genesove/Mayer 2001), futures markets (e.g., Choe/Eom 2009), and stock markets (Kliger/Kudryavtsev 2008; Shefrin/Statman 1985). Because the emergence of the disposition effect has already been confirmed in offline experimental stock market simulations, for example, by Weber/Camerer (1998) or Chui (2001), we are confident that the disposition effect (as it has been defined in previous research) also emerges in experimental online stock markets. We therefore present the following baseline hypothesis:

H1: Individual online investors are more likely to sell stocks when the selling price is above last period's price than when the selling price is below last period's price (= disposition effect).

\subsection{Debiasing the Disposition Effect on the Individual-Investor Level}

In general, adequate measures to mitigate the disposition effect should focus on the decision maker, that is, "the perfectible individual" (Fischhoff 1982, p. 424). Increasing the decision maker's awareness of the threats of biases is considered an effective method of enhancing rationality in decision making amid risk and uncertainty (Bazerman 1998; Kaufmann et al. 2009). Accordingly, we expect direct debiasing of the disposition effect by means of informative feedback on (faulty) investors' trading actions to be an effective debiasing strategy. Financial investment decisions in private stock trading must always be made amid risk and uncertainty, and the disposition effect and its negative consequences are linked to irrationality, which might be reduced by raising the awareness of the disposition effect.

One debiasing strategy that contains elements of information and education for debiasing the disposition effect has already been proposed theoretically by Dhar/Zhu (2006). Based on an analysis of individual differences regarding the disposition effect across investors, these researchers concluded that a large fraction of individual investors were reluctant to realize their losses. Because this reluctance to realize losses (which is part of the disposition effect) might result in even sharper losses for individual investors, Dhar/Zhu (2006) suggested that brokerage firms should "try to educate their clients about the disposition effect" (Dhar/Zhu 2006, p. 727). Similarly, Bhandari/Hassanein (2012) advocate warnings about the disposition effect and its possible consequences.

However, ambiguous results have been found in empirical studies that use informative feedback as a debiasing strategy to address different biases in contexts other than financial decision-making contexts. Whereas studies by Lichtenstein/Fischhoff (1980) and Dougherty (2001) confirmed feedback as a successful method of reducing overconfidence in probability assessment tasks, this intervention did not prove to be effective in lowering overconfidence in other studies (e.g., Hammond et al. 1973; Sieck/Arkes 2005). Studies that used informative feedback as a debiasing strategy to reduce overconfidence generally implemented a calibration training session in which participants estimated confidence intervals and received outcome feedback to enhance learning. Subsequently, test blocks in which the individual level of overconfidence was measured were used. In other words, participants in those studies did not receive immediate feedback within the task but received upfront calibration training in separate sessions.

Similarly, to debias the disposition effect, Lee et al. (2008) successfully implemented training in probability-expectancy calculation. However, to date, informative feedback during the task has not been investigated regarding the disposition effect. Based on the suggestions by Dhar/Zhu (2006) as well as Bhandari/Hassanein (2012), we suggest that informative feedback during the task is a valid debiasing strategy for mitigating the disposition effect in individual investment decisions. We therefore propose the following hypothesis:

H2: Debiasing by means of informative feedback mitigates the disposition effect on individual investor's investment decisions.

In addition to informative feedback, we argue that providing information regarding human emotions involved in trading decisions is a promising direct debiasing strategy. In the previous literature, emotions have been shown to be particularly important in decision-making situations amid risk and uncertainty (Clore 1992; Forgas 1995; Isen 2008; Lerner/Keltner 2000; Loewenstein et al. 2001; Schwarz 1990; Weber/Johnson 2009). With regard to the disposition effect, the emotions of regret ("an emotional feeling associated with the ex post knowledge that a different past decision would have fared better than the one chosen", Shefrin/Statman 1985, p. 781) and pride as its "positive counterpart" (Shefrin/Statman 1985, p. 781) are discussed in the previous literature (Summers/Duxbury 2012).

Summers/Duxbury (2012), amongst others, showed that the specific emotions of pride and regret are necessary causes for the disposition effect to emerge. Investors' emotions were particularly evoked when investors held stocks that lost value. In this case, the regret experienced by investors caused them to hold onto their losing stocks too long. Similarly, Fogel/Berry (2006) observed that more investors feel regret about holding losing stocks too long than 
about selling winning stocks too soon.

Empirical findings in psychological research suggest that directing participants' attention to the influence of affective states on judgments or raising participants' awareness of emotion-related biases can result in a self-correction of participants' judgments (DeSteno et al. 2000; Dunn/Schweitzer 2005; Strack et al. 1993). Therefore, we expect that informing participants that pride and regret are associated with the emergence of the disposition effect will result in corrections of trading decisions, thereby reducing the disposition effect. That is, we assume that, in addition to general informative warnings, feedback on involved emotions in this context might be effective for lowering the disposition effect. Accordingly, in line with hypothesis 2, we propose the following hypothesis:

H3: Debiasing by means of feedback on involved emotions in trading mitigates the disposition effect on individual investor's investment decisions.

Because some investors might be more receptive to rational warnings whereas others might be more receptive to information on involved emotions, one might expect that combining both debiasing strategies is more effective than using only one of these; that is, applying both strategies will reduce the rate of people unaffected by an intervention. Therefore, we propose the following hypothesis:

H4: Debiasing by means of informative feedback in combination with debiasing by means of feedback on involved emotions in trading lowers the disposition effect more than the separate use of one of these debiasing strategies.

\section{Data and Method}

\subsection{Experimental Design and Procedure}

Our online experiment is based on the established procedure of Weber/Camerer (1998) which aims to examine the disposition effect. Participants are placed into a portfolio decision situation and instructed to manage a portfolio consisting of as many as six stocks that can be traded at announced prices before each of 14 periods. For the disposition effect to emerge, it is crucial that individuals feel responsible for their decisions and their own portfolio (Lee et al. 2008; Lehenkari 2011). For this reason and because we wanted a realistic investment situation, each participant received a simulated individual account of 10,000 EUR at the beginning of the experiment and could build the portfolio from scratch (Weber/Camerer 1998).

The prices of the six stocks (labeled A to F) were not influenced by the trading decisions of the study's participants. Specifically, probabilities as well as price increases and decreases were predetermined as follows: The chances of a price increase were $65 \%$ for stock C, $55 \%$ for stock E, $50 \%$ each for stocks A and D, $45 \%$ for stock B, and $35 \%$ for stock F. The probability of a decline in a certain stock price was always one minus the probability that it would increase. Price increases and decreases were predefined to be 1 EUR, 3 EUR, or 5 EUR and the probability of each of these increases or decreases to occur was one third. Participants could neither borrow money nor sell stocks short and no interest was paid on cash amounts. These settings completely parallel those of Weber/Camerer (1998), except for the fact that our currency was EUR.

We first provided our participants with instructions regarding the rules, including a detailed description of the way in which stock prices were determined. These instructions could be reread at any time during the simulation. Participants then viewed the stock price development over the three previous periods $\left(\mathrm{t}_{-1}, \mathrm{t}_{-2}, \mathrm{t}_{-3}\right)$, before making their first investment decision.

The participants received a fixed amount of 2.50 EUR each. To induce personal involvement in the investment decisions, participants additionally received a percentage of their winnings in the simulation (i.e., $0.25 \%$ ). Including the fixed amount, participants earned a total of $M=4.87 \mathrm{EUR}(S D=4.29, M I N=2.50, M A X=27.15)$.

We implemented a 2 (rational debiasing: present vs. not present) $\times 2$ (emotional debiasing: present vs. not present) between-participants design (cf. Charness et al. 2012). All participants were confronted with the same portfolio management task, which in the debiasing conditions was supplemented by an intervention.

\subsection{Measures}

\subsubsection{Independent Measures}

The debiasing intervention was implemented each time before the participants made an investment decision. The debiasing messages appeared on the computer screen whenever an investor held a stock that had lost value over the last period because reluctance of investors to realize losses has proven to be both pervasive and costly (e.g., Locke 2010). Because we did not want to confuse investors with excessive debiasing messages, no messages were implemented that warned investors not to sell stocks that had gained in value. (This side of the disposition effect is 
not as detrimental as the one involving losses, because investors are especially reluctant to realize losses in the loss domain. When selling stocks that have gained in value, investors only lose potential gains, whereas when failing to sell stocks that have lost value, investors lose their stakes.). In line with Weber/Camerer (1998), the previous period's prices served as reference prices (also see Baucells et al. 2011; Camerer 2000; Frazzini 2006).

To ensure that our debiasing interventions are realistic, we used debiasing messages that only briefly informed our participants about the disposition effect in trading and warned them not to fall prey to this irrational behavior (Fischhoff 1982). The participants in the rational debiasing condition received an informative warning message. This debiasing message contained information regarding the mode of action of the disposition effect and instructive warnings not to fall prey to the effect (see Appendix A for the exact formulation). The participants in the emotional debiasing condition received information with regard to the feelings and emotions typically involved in trading (pride and regret), their impact on subsequent trading decisions, and instructions to avoid any influence of these feelings on investment decisions (see Appendix B for the exact formulation). The participants in the combined debiasing condition were confronted with a combined message composed of both the aforementioned debiasing interventions (see Appendix $\mathrm{C}$ for the exact formulation). For participants in the control condition, no debiasing was applied. Participants were randomly assigned to the different experimental conditions.

\subsubsection{Dependent Measures}

Our dependent variable, i.e., the disposition effect, was measured using two different methods (cf. Dhar/Zhu 2006). First, the disposition effect is the result of dividing "the difference in sales of winner and loser stocks [...] by the total number of sales by that subject" (Weber/Camerer 1998, p. 177). A positive value indicates that the disposition effect is present (Weber/Camerer 1998). For instance, an investor who sells stocks three times with a gain and once with a loss shows a disposition effect of $(3-1) /(3+1)=0.5$.

Second, we measured the disposition effect by relating actual sales to selling opportunities at a gain or at a loss (Odean 1998). Specifically, we counted the number of realized gains and losses as well as paper gains and paper losses whenever a participant decided to sell a stock. Realized gains (losses) are defined as the number of winner (loser) stocks sold; all other stocks in the portfolio are defined as paper winners or paper losers depending on whether the current stock price is higher or lower than the stock price in the previous trading period. The disposition effect is then calculated as the difference between the proportion of realized gains and the proportion of realized losses (Odean 1998). A positive value indicates that investors tend to realize more gains than losses and, therefore, that the disposition effect is present (Odean 1998). If we assume that the investor in the previous example who has sold three times with a gain and once with a loss had 26 paper gains and 18 paper losses, we obtain a disposition effect of $(3 /(3+26))-(1 /(1+18))=0.05$, which is considerably smaller than the disposition effect calculated based on the procedure of Weber/Camerer (1998).

In our sample, we found a substantial correlation between both indicators of the disposition effect, $r=.85, p<.001$. We calculated the disposition effect on individual investor level.

\subsection{Participants}

The participants were recruited in university lectures, investment clubs, and bankers' academies throughout German-speaking Europe, so that it is reasonable to assume that they had no prior knowledge of the Weber/Camerer (1998) experiment. Overall, data (for the investment simulation task and for the survey) were collected from 242 participants of whom 19 self-classified in the survey as having no investment experience. To ensure that the participants have at least some investment experience, prior to the analyses the latter 19 persons were excluded, thereby reducing our final sample to $N=223$ participants (51-61 respondents within each of the four experimental conditions).

The participants in our sample were between 18 and 84 years of age $(M=28.77, S D=12.90)$, and nearly all participants were male $(90.6 \%)$. The participants indicated an average investment experience of 8.44 years $(S D=$ $8.51, M I N=1, M A X=50)$.

\section{Experimental Results}

\subsection{The Replication of the Disposition Effect Analyses by Weber and Camerer (1998)}

According to our first hypothesis, participants sell more stocks when the stock price has increased than when it has decreased since the last period. Because this hypothesis only relates to participants who were not confronted with one of the debiasing messages, we only used data from the control condition (i.e., both interventions absent) to test H1. 
Because, per definition, a positive value for the disposition effect indicates that the disposition effect is present (Odean 1998; Weber/Camerer 1998), we tested whether the disposition effect was significantly greater than zero in the control condition. According to the procedure of Weber/Camerer (1998), the mean of the disposition effect $(M=$ $0.27, S D=0.74)$ was significantly greater than zero, $t(55)=2.77, p<.01$. Similarly, the emergence of the disposition effect $(M=0.14, S D=0.33)$ was significant according to the procedure of Odean $(1998), t(55)=3.08, p<.01$. Overall, these findings indicate that the study by Weber/Camerer (1998) was successfully replicated in our experimental online stock market, thus supporting $\mathrm{H} 1$.

\subsection{Analyses Regarding the Debiasing of the Disposition Effect}

According to $\mathrm{H} 2$ and $\mathrm{H} 3$, both rational and emotional debiasing should reduce the impact of the disposition effect on individual investors' investment decisions. To test these two hypotheses, we first tested whether the means of the disposition effect are also significantly different than zero in the rational, the emotional, and the combined debiasing intervention conditions. We expected that in the intervention conditions, the means of the disposition effect were not significantly different than zero (i.e., that investors do not have a tendency to realize more gains than losses) or even negative (i.e., that investors tend to realize more losses than gains).

According to the procedure of Weber/Camerer (1998), mean disposition effects in all debiasing conditions $\left(M_{\text {rational }}=\right.$ $\left.-0.42, S D_{\text {rational }}=0.56, M_{\text {emotional }}=-0.38, S D_{\text {emotional }}=0.59, M_{\text {combined }}=-0.50, S D_{\text {combined }}=0.52\right)$ were negative and significantly different than zero, $t \mathrm{~s}(50-60)>4.56, p \mathrm{~s}<.001$. The same pattern was found when following the procedure of Odean (1998), $M_{\text {rational }}=-0.24, S D_{\text {rational }}=0.30, M_{\text {emotional }}=-0.22, S D_{\text {emotional }}=0.30, M_{\text {combined }}=-0.29$, $\left.S D_{\text {combined }}=0.25, t \mathrm{~s}(50-60)>5.34, p \mathrm{~s}<.001\right)$. Mean disposition effects were significantly negative in any of the debiasing conditions, indicating that investors tend to sell more losing stocks than winning stocks when debiasing is applied. Thus, our findings indicate that the disposition effect was not present in the debiasing conditions. Correspondingly, the overall disposition effects were significantly smaller in the debiasing conditions than in the control condition - according to the procedures of Weber/Camerer (1998), $t \mathrm{~s}(98-103)>5.05, p \mathrm{~s}<.001$, as well as according to the procedures of Odean (1998), $t \mathrm{~s}(102-109)>5.87, p \mathrm{~s}<.001$. In sum, these findings suggest that the debiasing strategies that are applied in our experiment are effective in reducing the disposition effect, thereby confirming $\mathrm{H} 2$ and $\mathrm{H} 3$.

\subsection{The Analyses Regarding Differences in the Effectiveness of Debiasing Strategies under Investigation}

Our fourth hypothesis states that a combination of rational and emotional debiasing is more effective in reducing the disposition effect than either rational or emotional debiasing alone. To examine this hypothesis, we first tested whether the mean of the disposition effect in the combined debiasing condition significantly differs from the mean disposition effects in the rational-only as well as in the emotional-only debiasing conditions. Contradicting H4, this cannot be confirmed, neither according to the procedure of Weber and Camerer (1998), ts $(110-114)<1.17$, ns, nor based on the procedure of Odean (1998), $t \mathrm{~s}(110-114)<1.35, n s$. Although the combination of both interventions descriptively resulted in the lowest rate of the disposition effect, the combination of rational and emotional debiasing did not significantly outperform the single interventions (also see Figure 1). 

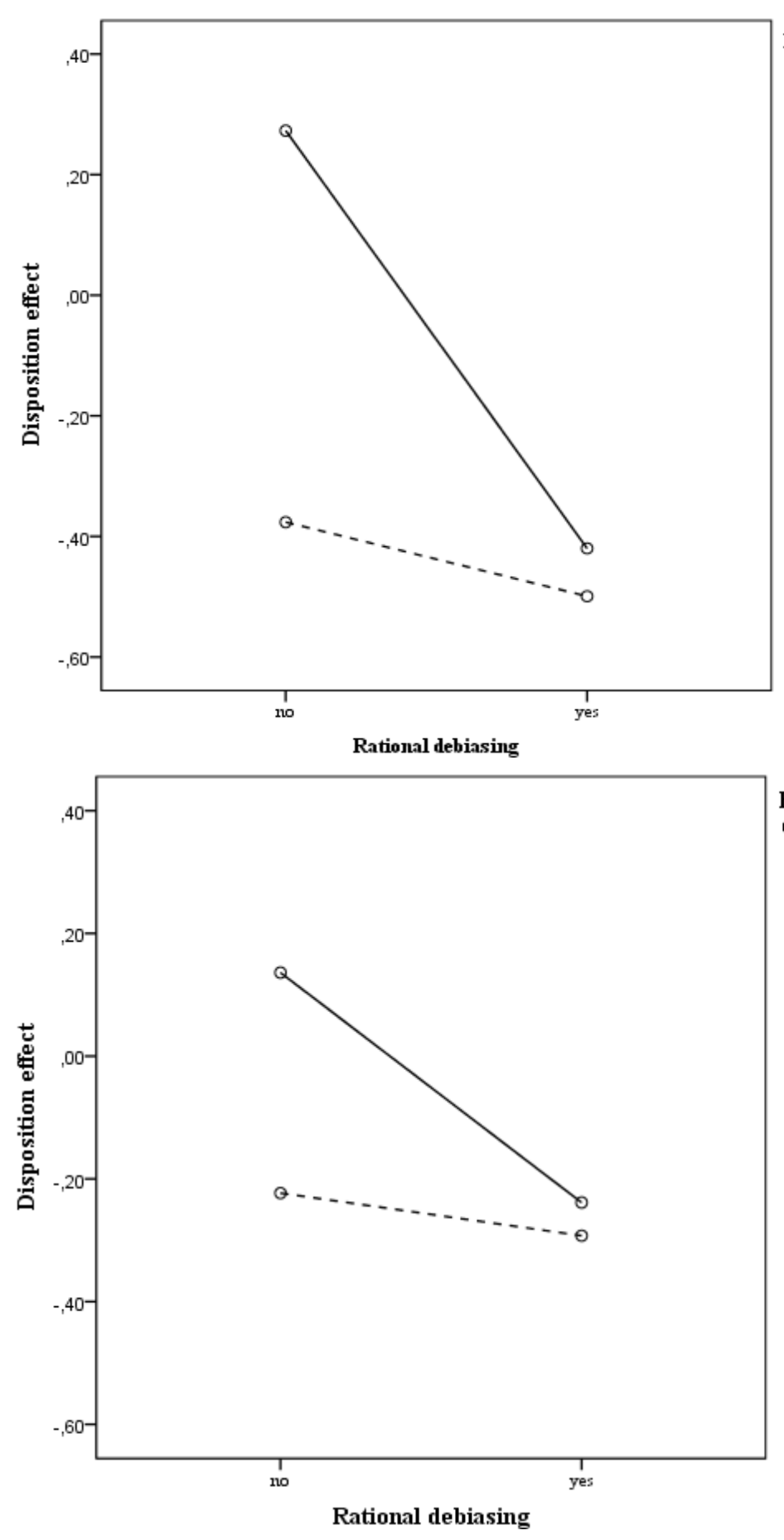

Emotional debiasing

- no

- - yes

Figure 1. The estimated marginal means of disposition effect by condition based on calculations proposed by Weber/Camerer (1998) (upper figure) and by Odean (1998) (lower figure)

Thus, H4, which states that combined debiasing has a stronger impact on reducing the disposition effect than the single debiasing strategies, cannot be supported by our analyses.

To further analyze the differences regarding the effectiveness of the debiasing strategies under investigation, we calculated the number of investors per experimental condition who were affected by the disposition effect (see Tables $1 \mathrm{a}$ and $1 \mathrm{~b})$. 
Table 1a. The number of "disposition investors" per experimental condition (disposition effect calculated based on Weber/Camerer (1998))

\begin{tabular}{lccc}
\hline & $\begin{array}{c}\text { Total number of investors } \\
\text { in this condition }\end{array}$ & $\begin{array}{c}\text { Number of investors } \\
\text { affected by the } \\
\text { disposition effect }\end{array}$ & $\begin{array}{c}\text { Percentage of investors } \\
\text { affected by the disposition } \\
\text { effect }\end{array}$ \\
\hline $\begin{array}{l}\text { Rational debiasing } \\
\text { condition }\end{array}$ & 55 & 11 & $20.0 \%$ \\
$\begin{array}{l}\text { Emotional debiasing } \\
\text { condition }\end{array}$ & 51 & 10 & $19.6 \%$ \\
$\begin{array}{l}\text { Combined debiasing } \\
\text { condition }\end{array}$ & 61 & 8 & $13.1 \%$ \\
Control condition & 56 & 33 & $58.9 \%$ \\
\hline
\end{tabular}

Table 1b. The number of "disposition investors" per experimental condition (disposition effect calculated based on Odean (1998))

\begin{tabular}{lccc}
\hline & $\begin{array}{c}\text { Total number of investors } \\
\text { in this condition }\end{array}$ & $\begin{array}{c}\text { Number of investors } \\
\text { affected by the } \\
\text { disposition effect }\end{array}$ & $\begin{array}{c}\text { Percentage of investors } \\
\text { affected by the disposition } \\
\text { effect }\end{array}$ \\
\hline $\begin{array}{l}\text { Rational debiasing } \\
\text { condition }\end{array}$ & 55 & 10 & $18.2 \%$ \\
$\begin{array}{l}\text { Emotional debiasing } \\
\text { condition }\end{array}$ & 51 & 9 & $17.6 \%$ \\
$\begin{array}{l}\text { Combined debiasing } \\
\text { condition }\end{array}$ & 61 & 6 & $9.8 \%$ \\
Control condition & 56 & 31 & $55.4 \%$ \\
\hline
\end{tabular}

In the control condition, we observed that 58.9\% (Weber/Camerer 1998) and 55.4\% (Odean 1998) of our participants showed the disposition effect. In the rational-only debiasing condition, the disposition effect was present for $20.0 \%$ (Weber/Camerer 1998) and 18.2\% (Odean 1998) of our participants. In the emotional-only debiasing condition, similar results were obtained: 19.6\% (Weber/Camerer 1998) and 17.6\% (Odean 1998) of our participants showed the disposition effect in their trading behavior. In the combined debiasing condition, this rate was somewhat lower, namely 13.1\% (Weber/Camerer 1998) and 9.8\% (Odean 1998). Thus, the combined debiasing descriptively resulted in the lowest rate of "disposition investors" (cf. Grinblatt/Han 2005). However, this association between using one vs. two interventions and the number of investors showing a disposition effect was neither significant according to the procedure of Weber/Camerer (1998), $\chi^{2}(1)=1.21, n s$, nor according to the procedure of Odean (1998), $\chi^{2}(1)=1.99$, $n s$. Based on these findings, $\mathrm{H} 4$ again cannot be confirmed.

\section{Discussion and Conclusion}

This study sought to empirically examine the effectiveness of debiasing in lowering the disposition effect in private investment decisions. Confirming the previous research on the disposition effect (Weber/Camerer 1998), we observed a disposition effect in the absence of debiasing. Interestingly, we found that rational and emotional debiasing significantly lowered the emergence of the disposition effect in individual investment decisions. Furthermore, the combined application of rational and emotional debiasing was not significantly more effective than using either rational or emotional debiasing alone. Because the combined debiasing strategy resulted in a slightly lower percentage of "debiasing investors" than the rational-only or the emotional-only debiasing interventions and the combined debiasing intervention was as effective as the single strategies when considering the common welfare, the combined debiasing should be implemented in practice.

Overall, our study contributes to the previous literature on investment decision-making and particularly on the disposition effect. Our findings are the first regarding the impact of debiasing on the disposition effect in private investment decisions. Although scholars intuitively agree that debiasing is appropriate for reducing decision biases (Arkes 1991; Larrick 2004; Lilienfeld et al. 2009) and although the previous research has shown that this intuition is correct for different investment decision-making contexts (Bhandari et al. 2008; Lee et al. 2008; Simonson/Staw 1992), our study is the first to empirically analyze the effectiveness of rational and emotional debiasing strategies for 
directly lowering the emergence of the disposition effect (rather than limiting its consequences).

Given that the debiasing strategies used in our study are easily applicable to a broad range of private investors without specific preparatory training, addressing the emergence of the disposition effect by introducing such debiasing strategies appears to be more promising than continuously attempting to limit the consequences. One might argue that the debiasing strategies used in our study are also useful for reducing the disposition effect in managerial investment decisions, which bear the same risks as private investment decisions because managers also have a reference price in mind and, in general, strive for success in terms of money gained.

Furthermore, our study contributes to the previous literature on the topic of debiasing. Extending the previous research that has successfully revealed debiasing strategies for several influential biases, our study is the first (1) to investigate easy-to-implement debiasing strategies addressing the emergence of the disposition effect, (2) to show that informative warnings are generally effective in this context and (3) to give insights into differences with regard to the effectiveness of rational vs. emotional vs. combined debiasing. Our results suggest that combined debiasing by means of rational and emotional warnings is slightly (but not significantly) more effective for reducing the disposition effect for as many investors as possible and that combined debiasing does not differ significantly in its effectiveness toward minimizing the overall sum of losses (i.e., ignoring the number of investors who could profit from debiasing).

Overall, our study might contribute to more rational investment decision making of individual investors in the future, which would be of significant value for both individuals and financial corporations. The debiasing strategies under investigation in our study are comparably easy to implement because they do not require explicit and time-consuming investor training beforehand and are easy to use. By implementing informative warnings in their trading software, discount brokerage firms might inform their investors about the disposition effect and warn them to not fall prey to this bias while trading. Because this procedure is expected to improve individual investment performance, private investors should be open to such an implementation in the trading system, and online brokerage firms could market this decision support as a special service and a unique selling point to potential clients.

Future research in this field may build on the results of this study in a number of ways. First, future research that replicates and extends our study is essential to further test the robustness of our findings. In particular, future research should test our experimental results in practice, using (quasi-) experimental field studies (e.g., in collaboration with an online brokerage firm) to analyze whether our findings on debiasing by means of informational warnings are generalizable to the real investment decisions of private investors. We would expect that the effectiveness of our debiasing interventions is even more pronounced in real investment decisions. The reason for this expectation is that investors might take the informative warnings more seriously when using their own trading money.

Second, future research might investigate whether and how the effectiveness of our debiasing interventions can be further strengthened. One might consider changing the presentation format of the warning messages by including a graphical illustration of the personal losses accumulated thus far because previous research has recognized that the information presentation format matters in decision making (e.g., Kelton et al. 2010). Alternatively, one might consider instructing participants to note reasons why, for example, they would like to hold on to losing stocks, although previous research has shown that this accompanies with the negative effects of the disposition effect. Thereby, participants might be forced to critically reflect on whether their intended decision is appropriate and possibly change their mind and sell losing stocks.

An additional avenue for future research is to examine other groups of investors (e.g., institutional investors, managers who make investment decisions, and older private investors) as well as other debiasing strategies (e.g., indirect debiasing strategies; cf. Kahn et al. 2006). Hence, although our study allows us to causally conclude that informative warnings are effective in lowering the disposition effect and rendering investment decisions more rational in our "typical" investment decision situation, further research is required to pave the way for better optimized investment decisions by both institutional and private investors in the field.

\section{References}

Arkes, H. R. (1991). Costs and benefits of judgment errors: Implications for debiasing. Psychological Bulletin, 110, 486-498. http://dx.doi.org/10.1037/0033-2909.110.3.486

Baker, H. K., \& Nofsinger, J. R. (2002). Psychological biases of investors. Financial Services Review, 11, 97-116.

Barber, B. M., Lee, Y. T., \& Liu, Y. J. et al. (2007). Is the aggregate investor reluctant to realize losses? Evidence $\begin{array}{lllll}\text { from } & \text { Taiwan. } & \text { European }\end{array}$ 
http://dx.doi.org/10.1111/j.1468-036X.2007.00367.x

Barber, B. M., \& Odean, T. (2001). The internet and the investor. Journal of Economic Perspectives, 15, 41-54. http://dx.doi.org/10.1257/jep.15.1.41

Barber, B. M., \& Odean, T. (2002). Online investors: Do the slow die first? The Review of Financial Studies, 15, 455-487. http://dx.doi.org/10.1093/rfs/15.2.455

Baucells, M., Weber, M., \& Welfens, F. (2011). Reference-point formation and updating. Management Science, 57, 506-519. http://dx.doi.org/10.1287/mnsc.1100.1286

Bazerman, M. H. (1998). Judgment in managerial decision making. John Wiley \& Sons, New York

Benartzi, S., \& Thaler, R. H. (2001). Naive diversification strategies in defined contribution saving plans. The American Economic Review, 91, 79-98. http://dx.doi.org/10.1257/aer.91.1.79

Bhandari, G., \& Hassanein, K. (2012). An agent-based debiasing framework for investment decision-support systems. Behaviour and Information Technology, 31, 495-507. http://dx.doi.org/10.1080/0144929X.2010.499477

Bhandari, G., Hassanein, K., \& Deaves, R. (2008). Debiasing investors with decision support systems: An experimental investigation. Decision Support Systems, 46, 399-410. http://dx.doi.org/10.1016/j.dss.2008.07.010

Camerer, C. (2000). Prospect theory in the wild: Evidence from the field. In Kahneman, D., \& Tversky, A. (Eds.), Choices, values, and frames. Cambridge University Press, Cambridge, UK

Camerer, C. (2003). The behavioral challenge to economics: Understanding normal people. Paper presented at the Federal Reserve Bank of Boston meeting on "How humans behave", Boston.

Charness, G., Gneezy, U., \& Kuhn, M. (2012). Experimental methods: Between-subject and within-subject design. Journal of Economic Behavior and Organization, 81, 1-8. http://dx.doi.org/10.1016/j.jebo.2011.08.009

Choe, H., \& Eom, Y. (2009). The disposition effect and investment performance in the future market. Journal of Future Markets, 29, 496-522. http://dx.doi.org/10.1002/fut.20398

Chui, P. M. W. (2001). An experimental study of the disposition effect: Evidence from Macau. The Journal of Psychology and Financial Markets, 2, 216-222. http://dx.doi.org/10.1207/S15327760JPFM0204_6

Clore, G. L. (1992). Cognitive phenomenology: feelings and the construction of judgment. In Martin, L. L., \& Tesser, A. (Eds.), The construction of social judgments. Lawrence Erlbaum Associates, Hillsdale, NJ

Coval, J. D., \& Shumway, T. (2005). Do behavioral biases affect prices? Journal of Finance, 60, 1-34. http://dx.doi.org/10.1111/j.1540-6261.2005.00723.x

Das, A. (2012). Estimating the loss from the disposition effect: A simulation study. Journal of Behavioral Finance, 13, 1-10. http://dx.doi.org/10.1080/15427560.2011.620722

Deaves, R. (2004). Data-conditioning biases, performance, persistence and flows: The case of Canadian equity funds. Journal of Banking and Finance, 28, 673-694. http://dx.doi.org/10.1016/S0378-4266(03)00042-6

DeSteno, D., Petty, R. E., \& Wegener, D. T. et al. (2000). Beyond valence in the perception of likelihood: The role of emotion specificity. Journal of Personality and Social Psychology, 78, 397-416. http://dx.doi.org/10.1037/0022-3514.78.3.397

Dhar, R., \& Zhu, N. (2006). Up close and personal: Investor sophistication and the disposition effect. Management Science, 52, 726-740. http://dx.doi.org/10.1287/mnsc.1040.0473

Dougherty, M. R. P. (2001). Integration of the ecological and error models of overconfidence using a multiple-trace memory model. Journal of Experimental Psychology: General, 130, 579-599. http://dx.doi.org/10.1037/0096-3445.130.4.579

Dunn, J. R., \& Schweitzer, M. E. (2005). Feeling and believing: The influence of emotion on trust. Journal of Personality and Social Psychology, 88, 736-748. http://dx.doi.org/10.1037/0022-3514.88.5.736

Fennema, M. G., \& Perkins, J. D. (2008). Mental budgeting versus marginal decision making: Training, experience and justification effects on decisions involving sunk costs. Journal of Behavioral Decision Making, 21, 225-239. http://dx.doi.org/10.1002/bdm.585

Fischhoff, B. (1982). Debiasing. In Kahneman, D., Slovic, P., \& Tversky, A. (Eds.), Judgment under uncertainty: Heuristics and biases. Cambridge University Press, Cambridge. http://dx.doi.org/10.1017/CBO9780511809477.032 
Fogel, S. O., \& Berry, T. (2006). The disposition effect and individual investor decisions: The roles of regret and counterfactual alternatives. Journal of Behavioral Finance, 7, 107-116. http://dx.doi.org/10.1207/s15427579jpfm0702_5

Forgas, J. P. (1995). Mood and judgment: The affect infusion model (AIM). Psychological Bulletin, 117, 39-66. http://dx.doi.org/10.1037/0033-2909.117.1.39

Frazzini, A. (2006). The disposition effect and underreaction to news. Journal of Finance, 61, 2017-2046. http://dx.doi.org/10.1111/j.1540-6261.2006.00896.x

Genesove, D., \& Mayer, C. (2001). Loss aversion and seller behavior: Evidence from the housing market. The Quarterly Journal of Economics, 116, 1233-1260. http://dx.doi.org/10.1162/003355301753265561

Ghosh, D. (1997). De-escalation strategies: Some experimental evidence. Behavioral Research in Accounting, 9, $88-112$.

Glode, V. (2011). Why mutual funds "underperform". Journal of Financial Economics, 99, 546-559. http://dx.doi.org/10.1016/j.jfineco.2010.10.008

Grinblatt, M., \& Han, B. (2005). Prospect theory, mental accounting, and momentum. Journal of Financial Economics, 78, 311-339. http://dx.doi.org/10.1016/j.jfineco.2004.10.006

Hammond, K. R., Summers, D. A., \& Deane, D. H. (1973). Negative effects of outcome-feedback in multiple-cue probability learning. Organizational Behavior and Human Performance, 9, 30-34. http://dx.doi.org/10.1016/0030-5073(73)90034-2

Isen, A. M. (2008). Some ways in which positive affect influences decision making and problem solving. In Lewis M, Haviland-Jones, J. M., \& Feldman, Barrett L. (Eds.), Hanbook of emotions (3 ed.). Guilford Publications, New York, NY

Kahn, B. E., Luce, M. F., \& Nowlis, S. M. (2006). Debiasing insights from process tests. Journal of Consumer Research, 33, 131-138. http://dx.doi.org/10.1086/500492

Kaufmann, L., Michel, A., \& Carter, C. R. (2009). Debiasing strategies in supply management decision-making. Journal of Business Logistics, 30, 85-106. http://dx.doi.org/10.1002/j.2158-1592.2009.tb00100.x

Kelton, A. S., Pennington, R. R., \& Tuttle, B. M. (2010). The effects of information presentation format on judgment and decision making: A review of the information systems research. Journal of Information Systems, 24, 79-105. http://dx.doi.org/10.2308/jis.2010.24.2.79

Kliger, D., \& Kudryavtsev, A. (2008). Reference point formation by market investors. Journal of Banking and Finance, 32, 1782-1794. http://dx.doi.org/10.1016/j.jbankfin.2007.12.006

Konanaa, P., \& Balasubramanian, S. (2005). The Social-Economic-Psychological Model of technology adoption and usage: An application to online investing. Decision Support Systems, 39, 505-524. http://dx.doi.org/10.1016/j.dss.2003.12.003

Larrick, R. P. (2004). Debiasing. In: Koehler, D. J., \& Harvey, N. (Eds.), Blackwell handbook of judgment and decision making. Blackwell Publishing, Malden. http://dx.doi.org/10.1002/9780470752937.ch16

Lee, H.J., Park, J., \& Lee J.Y. et al. (2008). Disposition effects and underlying mechanisms in e-trading of stocks. Journal of Marketing Research, 45, 362-378. http://dx.doi.org/10.1509/jmkr.45.3.362

Lehenkari, M. (2011). In search of the underlying mechanism of the disposition effect. Journal of Behavioral Decision Making, 25, 196-209. http://dx.doi.org/10.1002/bdm.727

Lehenkari, M., \& Perttunen, J. (2010). Holding on to the losers: Finnish evidence. In Bruce, B. (Ed.), Handbook of behavioral finance. Edward Elgar Publishing, Cheltenham, UK. http://dx.doi.org/10.4337/9781849809108.00027

Lerner, J. S., \& Keltner, D. (2000). Beyond valence: Toward a model of emotion-specific influences on judgement and choice. Cognition \& Emotion, 14, 473-493. http://dx.doi.org/10.1080/026999300402763

Lichtenstein, S., \& Fischhoff, B. (1980). Training for calibration. Organizational Behavior and Human Performance, 26, 149-150. http://dx.doi.org/10.1016/0030-5073(80)90052-5

Lilienfeld, S. O., Ammirati, R., \& Landfield, K. (2009). Giving debiasing away: Can psychological research on correcting cognitive errors promote human welfare? Perspectives on Psychological Science, 4, 390-398. 
http://dx.doi.org/10.1111/j.1745-6924.2009.01144.x

Locke, P. (2010). Derivate markets. In Baker, H. K., \& Nofsinger, John R. (Eds.), Behavioral finance: Investors, corporations, and markets. John Wiley and Sons, Hoboken, NJ

Loewenstein, G. F., Weber, E. U., \& Hsee, C. K. et al (2001). Risk as feelings. Psychological Bulletin, 127, 267-286. http://dx.doi.org/10.1037/0033-2909.127.2.267

Milkman, K. L., Chugh, D., \& Bazerman, M. H. (2009). How can decision making be improved? Perspectives on Psychological Science, 4, 379-383. http://dx.doi.org/10.1111/j.1745-6924.2009.01142.x

Odean, T. (1998). Are investors reluctant to realize their losses? Journal of Finance, 53, 1775-1798. http://dx.doi.org/10.1111/0022-1082.00072

Richards, D., Rutterford, J., \& Fenton, O'Creevy, M. (2011). Do stop losses work? The disposition effect, stop losses and investor demographics. Working Paper. The Open University Business School. Milton Keynes, UK.

Ringov, D. (2012). Can organizations mitigate individual biases? Evidence from mutual fund investment decisions. Paper presented at the DRUID conference, June 2012 in Copenhagen, Denmark.

Roger, P. (2009). Does the consciousness of the disposition effect increase the equity premium? Journal of Behavioral Finance, 10, 138-151. http://dx.doi.org/10.1080/15427560902904628

Schwarz, N. (1990). Feelings as information: Informational and motivational functions of affective states. In Higgins, E. T., \& Sorrentino, R. M. (Eds.), Handbook of motivation and cognition: Foundations of social behavior. Guilford Press, New York

Shapira, Z., \& Venezia, I. (2001). Patterns of behavior of professionally managed and independent investors. Journal of Banking and Finance, 25, 1573-1587. http://dx.doi.org/10.1016/S0378-4266(00)00139-4

Shefrin, H., \& Statman, M. (1985). The disposition to sell winners too early and ride losers too long: Theory and evidence. Journal of Finance, 40, 770-790. http://dx.doi.org/10.1111/j.1540-6261.1985.tb05002.x

Sieck, W. R., \& Arkes, H. R. (2005). The recalcitrance of overconfidence and its contribution to decision aid neglect. Journal of Behavioral Decision Making, 18, 29-53. http://dx.doi.org/10.1002/bdm.486

Simonson, I., \& Nye, P. (1992). The effect of accountability on susceptibility to decision errors. Organizational Behavior and Human Decision Processes, 51, 416-446. http://dx.doi.org/10.1016/0749-5978(92)90020-8

Simonson, I., \& Staw, B. M. (1992). Deescalation strategies: A comparison of techniques for reducing commitment to losing courses of action. Journal of Applied Psychology, 77, 419-426. http://dx.doi.org/10.1037/0021-9010.77.4.419

Soman, D., \& Liu, M. W. (2011). Debiasing or rebiasing? Moderating the illusion of delayed incentives. Journal of Economic Psychology, 32, 307-316. http://dx.doi.org/10.1016/j.joep.2010.12.005

Stanovich, K. E., \& West, R. F. (2000). Individual differences in reasoning: Implications for the rationality debate? Behavioral and Brain Sciences, 23, 645-726. http://dx.doi.org/10.1017/S0140525X00003435

Strack, F., Schwarz, N., \& Bless, H. et al (1993). Awareness of the influence as a determinant of assimilation versus contrast. European Journal of Social Psychology, 23, 53-62. http://dx.doi.org/10.1002/ejsp.2420230105

Summers, B., \& Duxbury, D. (2012). Decision-dependent emotions and behavioral anomalies. Organizational Behavior and Human Decision Processes, 118, 226-238. http://dx.doi.org/10.1016/j.obhdp.2012.03.004

Von Neumann, J., \& Morgenstern, O. (1944). Theory of games and economic behavior. Princeton University Press, Princeton

Weber, E., \& Johnson, E. J. (2009). Mindful judgment and decision making. Annual Review of Psychology, 60, 53-85. http://dx.doi.org/10.1146/annurev.psych.60.110707.163633

Weber, M., \& Camerer, C. F. (1998). The disposition effect in securities trading: An experimental analysis. Journal of Economic Behavior and Organization, 33, 167-184. http://dx.doi.org/10.1016/S0167-2681(97)00089-9 


\section{Appendix}

\section{A. Debiasing intervention: Rational debiasing condition}

\section{Information for maximizing your investment performance}

Investors typically fall prey to the following two types of investment flaws:

1. They sell winning stocks too early.

2. They hold losing stocks for too long.

Losing stocks are held because investors hope that prices will recover, whereas winning stocks are hastily sold to protect gains.

This behavior, however, has turned out to adversely affect investors. Previous research has shown that it is generally advantageous for investors to hold winning stocks and to limit losses by selling losing stocks. During this simulation you are expected to maximize your portfolio value. Please keep this information in mind while trading, particularly remembering which stocks should be sold at which point in time. You can, for instance, think of specific thresholds at which you sell a specific stock in any case.

\section{B. Debiasing intervention: Emotional debiasing condition}

\section{Information for maximizing your investment performance}

When trading stocks, investors are typically strongly influenced by their feelings. This pitfall can be noticed in the following two different situations:

1. If the price of a recently bought stock has risen, many investors feel pride because of their good market timing and sell these stocks, realizing only small gains. This behavior, however, shortens potential future gains.

2. If the price of a recently bought stock has fallen, investors try to avoid feelings of regret by holding these stocks, hoping that prices will recover in the future. Additionally, in their own defense and because they do not want to admit that they have chosen the wrong stock, investors are inclined not to realize losses but rather to wait until the price recovers.

Please try not to be driven by emotions when deciding to buy/sell stocks!

\section{Debiasing intervention: Combined debiasing condition}

\section{Information for maximizing your investment performance}

Investors typically fall prey to two the following types of investment flaws:

1. Due to the experience of pride of a right decision, they sell winning stocks too early.

2. To avoid regret that a buy decision was wrong, they hold losing stocks for too long.

Losing stocks are held because investors hope that prices will recover, whereas winning stocks are hastily sold to protect gains.

This behavior, however, has turned out to adversely affect investors. Previous research has shown that it is generally advantageous for investors to hold winning stocks and to limit losses by selling losing stocks. During this simulation you are expected to maximize your portfolio value. Please keep this information in mind while trading, particularly remembering which stocks should be sold at which point in time. Try to avoid being driven by emotions such as pride or regret when trading. You can, for instance, think of specific thresholds at which you sell a specific stock in any case. Please try not to be driven by emotions when deciding to buy/sell stocks! 